\title{
PENGARUH POLA MAKAN TERHADAP HIPERTENSI PADA LANSIA (Studi Di Posyandu Kutilang 1 Kelurahan Pangkut Kecamtan Arut Utara Kotawaringin Barat Kalimantan Tengah)
}

\author{
Yohanes Sukri $^{1}$ Agung Setyono Wibowo $^{2}$ Wahyono $^{3}$ \\ ${ }^{123}$ STIKes Borneo Cendekia Medika Pangkalan Bun \\ 1email : yohanessukri@gmail.com, ${ }^{2}$ email : agungwibowo@gmail.com, ${ }^{3}$ email :
} wahyono@gmail.com

\begin{abstract}
ABSTRAK
Pendahuluan: Masalah hipertensi menjadi salah satu penyakit mematikan di dunia dan tanpa di sadari akan menimbulkan komplikasi yang cukup berat dan beresiko mengakibatkan kematian. Kejadian hipertensi lebih banyak dan sering di alami oleh lansia yang penyebab utamanya di pengaruhi oleh pola makan. Penelitian ini bertujuan mencari pengaruh pola makan terhadap hipertensi pada lansia di posyandu kutilang 1 kelurahan pangkut kecematan arut utara kotawaringin barat kalimantan tengah. Bahan dan metode penelitian: Jenis penelitian adalah analitik dengan pendekatan analitik-cross sectional. Populasinya seluruh lansia yang menderita hipertensi sebanyak 70 orang. Teknik sampling yang di gunakan adalah proporsional cluster random sampling sehingga didapatkan sampel 41 responden. Instruman penelitian menggunakan lembar koesioner, dimana variabel independen adalah pola makan pada lansia penderita hipertensi dan variabel dependen adalah hipertensi pada lansia. Hasil penelitian: Hasil penelitian menunjukan diketahui sebagian besar pola makan responden pada posyandu kelurahan Pangkut adalah cukup sebanyak 21 orang $(51,2 \%)$. Dan diketahui hampir setengahnya lansia di posyandu kelurahan pangkut adalah hipertensi sedang sebanyak 15 orang $(31.7 \%)$. Hasil penelitian: dengan uji ranks spearman terdapat pengaruh pola makan terhadap hipertensi dengan tingkat siknifikan $\mathrm{p}=0,037$. Kesimpulan: Dalam penelitian ini adalah terdapat pengaruh signifikan antara pola makan terhadap hipertensi di posyandu kutillang 1 kelurahan pangkut kecamatan arut utara kotawaringin barat kalimantan tengah. Saran Bagi lansia ini dapat dilakukan untuk tindakan, Bagi Posyandu agar dapat melakukan tindak lanjut penyuluhan,bagi peneliti selanjutnya agar dapat melakukan pengkajian ulang.
\end{abstract}

Kata kunci: Hipertensi, Lansia, Pola makan.

The INFLUENCE of DIET AGAINST HYPERTENSION in the ELDERLY (studies in Neighborhood 1 Kutilang Posyandu Pangkut Kecamtan North West Kotawaringin Arut Central Kalimantan)

\section{ABSTRACT}

Preliminary: The problem of hypertension became one of the deadly disease in the world and without complications will realize a fairly heavy and are at risk of resulting in death. The incidence of hypertension and more often in the elderly by natural causes of its influence by diet. This research aims to find the influence of diet against hypertension in elderly at posyandu kutilang 1 kelurahan pangkut North 
West kotawaringin arut kecematan Central kalimantan. Redearch methods: This type of research is the analytic analytic approach-cross sectional. The population of the entire elderly suffering from hypertension as many as 70 people. The sampling technique used was proportional cluster random sampling so obtained a sample of 41 respondents. Instruman research using sheets of koesioner, where the independent variable is a pattern of eating on the elderly sufferers of hypertension and the dependent variable is the hypertension in the elderly. The results of the research: the research results show the known most of the eating patterns of respondents at posyandu village Pangkut was quite as much as 21 people (51.2\%). And is known to almost half of the elderly in the village pangkut posyandu is hypertension are as many as 15 people (31.7\%). Results and discussion: with the test ranks spearman there is influence of diet against hypertension with a level of significance $p=0,037$. Conclusion: In this study there was significant influence between the diet against hypertension in pangkut village kutillang posyandu 1 North West kotawaringin arut subdistrict of Central kalimantan. Suggestions For this elderly can be done for action, For Posyandu to be able to do follow-up of counseling, for further researcher to be able to conduct review.

Keywords: hypertension, Elderly, diet.

\section{PENDAHULUAN}

Hipertensi merupakan salah satu penyakit mematikan di dunia. Hipertensi lebih banyak diderita oleh para lansia yang pola makannya tinggi lemak dan kolesterol. Tekanan darah tinggi atau hipertensi dapat terjadi saat aliran darah berusaha memberi tekanan yang lebih besar terhadap dinding pembuluh darah arteri, tekanan normal berkisar 120/90 mmHg.

Didapatkan data dari dinas kesehatan daerah Kabupaten Kotawaringin Barat 2014 bahwa jumlah penderita hipertensi di Kecamatan Arut Utara 938 sedangkan data hasil survei Puskesmas Artut Utara pada tahun 2016 menunjukan bahwa penderita hipertensi di Kelurahan Pangkut berjumlah 478. Berdasarkan data yang didapat di Posyandu Kutilang 1 pada tahun 2016 di Kelurahan Pangakut Kecamatan Arut Utara Kotawaringin Barat Kalimantan Tengah berjumlah 142 data yang didapat dari tiap RT di
Posyandu Kutilang 1 RT 04 dan RT 05 merupakan penderita hipertensi terbanyak berjumlah 70 orang. Semakin meningkatnya usia maka akan lebih beresiko terhadap peningkatan tekanan darah sistolik sedangkan diastolik meningkat hanya sampai usia 55 tahun. Laki-laki atau perempuan sama-sama memilik resiko hipertensi namun laki-laki lebih berisiko hipertensi di bandingkan perempuan saat usia $<45$ tahun tetapi saat usia $>65$ tahun perempuan lebih beresiko hipertensi (Junaidi, 2012, 89). Studi pendahuluan di lakukan di desa gandis kecamatan arut utara kotawaringin barat kalimantan tengah dengan 10 lansia penderita hipertensi terdapat 8 lansia penderita hipertensi yang memiliki pengaruh terhadap pola makan.

Makanan yang dapat memicu hipertensi merupakan makanan yang kurang sehat seperti makanan yang berlemak, makanan asin, makanna siap saji dan makanan kurang serat atau 
makanan yang mengandung kalium. konsumsi lemak yang berlebihan dapat menimbulkan resiko hipertensi karena akan meningkatkan kadar kolesterol dalam darah. kolesterol tersebut akan melekat pada dinding pembulu darah yang lama-kelamaan pembulu darah akan tersumbat di akibatkan adanya plaque dalam darah plaque yang terbentuk akan mengakibatkan aliran darah menyempit sehingga velome darah dan tekanan darah akan meningkat (morrell, 2011, 156). Makanan yang asin bisa menyebabkan hipertensi karena natrium (NA) sifatnya mengikat banyak air, maka makin tinggi garam membuat volume darah meningkat. Kurangnya mengkonsumsi sumber makanan yang mengandung kalium(K) atau kurang serat akan mengakibatkan jumlah natrium menumpuk dan akan meningkatkan resiko hipertensi kerena ada tekanan pada detak jantung (Junaidi, 2012, 130).

Berdasarkan keterangan diatas maka dapat di ketahui jenis makanan berpengaruh terhadap hipertensi untuk itu perlu dilakukan pengkajian lebih mendalam pada masyarakat dengan judul: pengaruh pola makan terhadap kejadian hipertensi pada lansia di Posyandu Lansia Kelurahan Pangkut Kecamatan Arut Utara Kotawaringin Barat Kalimantan Tengah.

\section{METODE PENELITIAN}

Dalam penelitian ini jenis penelitian yang digunakan adalah penelitian analitik. hasil penelitian diolah dengan menggunakan uji statistik non parametrik. Sedangkan rancangan penelitian yang digunakan adalah cross sectional (Nursalam 2015, 78).
Penelitian ini berjenis analitik dengan pendekatan analitik-cross sectional. Populasinya seluruh lansia yang menderita hipertensi sebanyak 70 orang. Tehnik samling yang di gunakan adalah proporsional cluster random sampling sehingga didapatkan sampel 41 responden. Instruman penelitian menggunakan lembar koesioner, dimana variabel independen adalah pola makan pada lansia penderita hipertensi dan variabel dependen adalah hipertensi pada lansia

Hasil penelitian menunjukan diketahui sebagian besar pola makan responden pada posyandu kelurahan Pangkut adalah cukup sebanyak 21 orang (51,2\%). Dan diketahui hampir setengahnya lansia di posyandu kelurahan pangkut adalah hipertensi sedang sebanyak 15 orang (31.7\%). Hasil penelitian menunjukan terdapat pengaruh pola makan terhadap hipertensi dengan tingkat siknifikan $\mathrm{p}=0,037$.

\section{HASIL PENELITIAN}

\section{Data umum}

Tabel 1 Distribusi frekuensi responden berdasarakan umur di posyandu kutilang 1 kelurahan pangkut Tahun $2017(n=41)$

\begin{tabular}{ccc}
\hline Umur & Jumlah & Persentase $(\%)$ \\
\hline $20-45$ & 0 & 0 \\
$46-60$ & 20 & $48,8 \%$ \\
$61-89$ & 21 & $51,2 \%$ \\
$>90$ & 0 & 0 \\
\hline Total & 41 & $100 \%$ \\
\hline
\end{tabular}

Sumber : Data primer 2017

Berdasarkan tabel 1 dapat menunjukkan bahwa sebagian besar responden berumurposyandu kutilang 1 
kelurahan pangkut di 60-89 tahun sebanyak 21 orang $(51,2 \%)$.

Tabel 2 Distribusi frekuensi Berdasarkan Jenis kelamin di posyandu kutilang 1 kelurahan pangkut Tahun $2017(\mathrm{n}=41)$

\begin{tabular}{ccc}
\hline $\begin{array}{c}\text { Jenis } \\
\text { kelamin }\end{array}$ & Jumlah & Persentase(\%) \\
\hline Laki-laki & 14 & $34,1 \%$ \\
Perempuan & 27 & $65,9 \%$ \\
\hline Total & 41 & $100 \%$ \\
\hline
\end{tabular}

Sumber : Data primer 2017

Berdasarkan tabel 2 dapat menunjukkan bahwa sebagian besar responden memiliki jenis kelamin perempuan diposyandu kutilang 1 kelurahan pangkut sebanyak 27 orang $(65,9 \%)$.

Tabel 3 Distribusi frekuensi berdasarkan pendidikan terakhir pasien di posyandu kutilang 1 kelurahan pangkut tahun $2017(\mathrm{n}=41)$

\begin{tabular}{ccc}
\hline $\begin{array}{c}\text { Tingkat } \\
\text { pendidikan }\end{array}$ & Jumlah & $\begin{array}{c}\text { Persentase } \\
(\%)\end{array}$ \\
\hline Tidak & 14 & $22,2 \%$ \\
sekolah & & \\
SD & 9 & $14,3 \%$ \\
SMP & 8 & $12,7 \%$ \\
SMA & 8 & $12,7 \%$ \\
Serjana & 2 & 3,2 \\
\hline Total & 41 & $100 \%$ \\
\hline
\end{tabular}

Sumber: data primer 2017

Pada tabel 3 Menunjukan bahwa hampir seluruhnya pendidikan terakhir responden posyandu kutilang 1 kelurahan pangkut SD dengan jumlah 23 orang $(56 \%)$.

Pada Tabel 4 Menunjukan bahwa hampir setengahnya responden memiliki pekerjaan di posyandu kutilang 1 kelurahan pangkut ibu rumah tangga dengan jumlah 14 orang $(34,1 \%)$

\begin{tabular}{ccc}
\hline Pekerjaan & Jumlah & Persentase(\%) \\
\hline Tidak & 10 & 24,4 \\
Bekerja & & \\
Tani & 0 & 0 \\
Swasta & 8 & 19,5 \\
PNS & 2 & 4,9 \\
Penambang & 7 & 17,1 \\
Ibu rumah & 14 & 34,1 \\
tangga & & \\
\hline Total & 41 & 100 \\
\hline
\end{tabular}

Sumber: data primer 2017

Pada Tabel 4 Menunjukan bahwa hampir setengahnya responden memiliki pekerjaan di posyandu kutilang 1 kelurahan pangkut ibu rumah tangga dengan jumlah 14 orang $(34,1 \%)$.

Tabel 5Distribusi responden berdasarkan Pendapatan Responden Di posyandu kutilang 1 kelurahan pangkut Tahun 2017

\begin{tabular}{lcc}
\hline Pendapatan & Jumlah & Persentase(\%) \\
\hline < 1 Juta & 10 & 24 \\
1-3 Juta & 25 & 61 \\
> 3 Juta & 6 & 15 \\
\hline Total & 41 & 100 \\
\hline Sumber: data primer 2017 \\
Dari tabel diatas diketahui Sebagian \\
besar responden di posyandu lansia \\
kutilang 1 kelurahan memiliki \\
pendapatan 1-3 juta yang berjumlah \\
25orang (61\%).
\end{tabular}

\section{Data Khusus}

Tabel 6 Distribusi Responden Berdasarkan pola makan responden Di posyandu kutilang 1 kelurahan pangkut Tahun 2017 


\begin{tabular}{lcc}
\hline Pola Makan & Jumlah & Persentase $(\%)$ \\
\hline Baik & 1 & 2,4 \\
Cukup & 21 & 51,2 \\
Kurang & 19 & 46,3 \\
\hline Total & 41 & 100 \\
\hline
\end{tabular}

Sumber: data primer 2017

Dari tabel 6 menunjukkan bahwa sebagian besar pola makan responden pada posyandu kelurahan Pangkut adalah cukup sebanyak 21 orang $(51,2 \%)$.

Tabel 7 Distribusi Responden Berdasarkan indikator hipertensi responden Di posyandu kutilang 1 kelurahan pangkut Tahun 2017

\begin{tabular}{ccc}
\hline TD & Jumlah & Persentase(\%) \\
\hline $\begin{array}{c}\text { Hipertensi } \\
\text { ringan }\end{array}$ & 9 & $22,0 \%$ \\
$\begin{array}{c}\text { Hipertensi } \\
\text { sedang }\end{array}$ & 15 & $36,6 \%$ \\
$\begin{array}{c}\text { Hipertensi } \\
\text { berat }\end{array}$ & 13 & $31,7 \%$ \\
$\begin{array}{c}\text { Hipertensi } \\
\text { sangat berat }\end{array}$ & 4 & $9,8 \%$ \\
\hline Total & 41 & $100 \%$ \\
\hline
\end{tabular}

Sumber: data primer 2017

Dari tabel 7 menunjukkan bahwa hampir setengahnya lansia di posyandu kelurahan pangkut adalah hipertensi sedang sebanyak 15 orang (36.6\%).

Tabel 8 Analisis pengaruh pola makan terhadap penderita hipertensi pada lansia

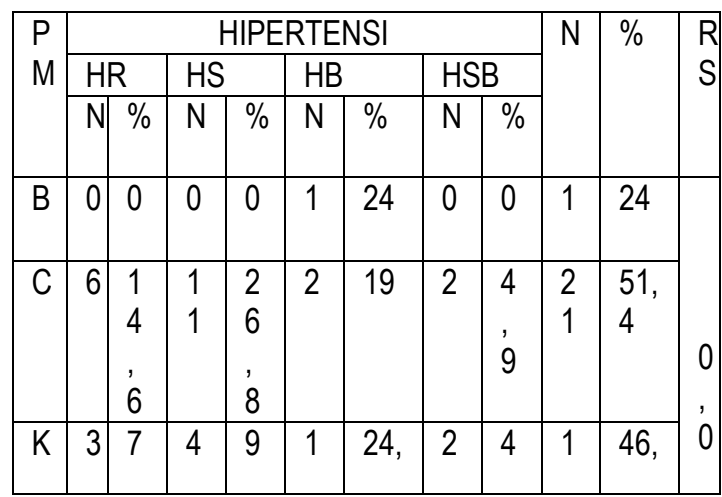

\begin{tabular}{|l|l|l|l|l|l|l|l|l|l|l|l|}
\hline & & 1 & & 1 & 0 & 4 & &, & 9 & 3 & 3 \\
& & 3 & & 8 & & & & 9 & & & 7 \\
\hline $\mathrm{T}$ & 9 & 2 & 1 & 3 & 1 & 31, & 4 & 9 & 4 & 10 & \\
& & 2 & 5 & 6 & 3 & 7 & & 1 & 0 & \\
& & & & & & & & & & \\
\hline
\end{tabular}

Dari tabel 8 diketahui sebagian besar pola makan dengan hipertensi sedang responden pada posyandu kelurahan Pangkut adalah sebanyak 11 orang (26,8\%). Selain itu, didapatkan hasil Rank Spearman 0,037 menunjukkan nilai $\mathrm{p}<0,05$ dengan bantuan aplikasi SPSS 16 sehingga $\mathrm{H}_{0}$ ditolak dan $\mathrm{H}_{1}$ diterima maka dapat dikatakan ada pengaruh pola makan terhadap hipertensi pada lansia di Posyandu Kutilang 1 Kelurahan Pangkut.

\section{PEMBAHASAN}

Dari tabel 6 menunjukkan bahwa sebagian besar pola makan responden pada posyandu kelurahan Pangkut adalah cukup sebanyak 21 orang $(51,2 \%)$.

Pada saat responden diberiakan pertanyaan tentang pola makan, responden menjawab selalu memakan asupan makanan yang cukup seperti; mei instan, cornet, sarden, gorengan, kulit ayam, daging sapi, sate, ikan asin. sehingga asupan gizi yang diperoleh responden cukup.

Jika memakan makanan seperti ini terus menerus maka akan menyebabkan tubuh bekerja sangat ekstra untuk menyerap zat-zat tersebut, sehingga meningkatkan detak jantung serta menyumbat pembuluh darah maka akan terjadi hipertensi (Junaidi, 2013, 45 ).

Berdasarkantabel 2 dapat menunjukkan bahwa sebagian besar responden memiliki jenis kelamin perempuan di 
posyandu kutilang 1 kelurahan pangkut sebanyak 27 orang $(65,9 \%)$. Wanita sering mengalami masalah sehingga mengakibatkan stress/ beban pikiran yang memberikan dampak akan pola makan wanita tersebut.

Banyak penelitian yang melaporkan bahwa wanita mudah mengalami kegemukan daripada pria. Sel lemak laki-laki lebih besar dari wanita disamping itu juga wanita mempunyai basal metabolisme rate (BMR) yang lebih rendah dibandingkan laki-laki (Simanjuntak, 2011 234)

Pada tabel 3 Menunjukan bahwa hampir seluruhnya pendidikan terakhir responden di posyandu lansia kutilang 1 kelurahan pangkut dengan pengetahuan rendah dengan jumlah 23 orang $(56 \%)$. Pola konsumsi makanan yang sehat cenderung dilakukan oleh mereka yang memiliki pengetahuan yang tinggi. Hal ini diasumsikan karena mereka lebih sadar akan kesehatan sehingga mempunyai gaya hidup yang lebih sehat. Orang yang berpendidikan yang lebih tinggi membantu dalam pembentukan konsep antara pola konsumsi makanan dan kesehatan pada setiap individu .

Pada Tabel 4 Menunjukan bahwa hampir setengahnya responden memiliki pekerjaan di posyandu kutilang 1 kelurahan pangkut ibu rumah tangga de ngan jumlah 14 orang $(34,1 \%)$. Pekerjaan berhubungan juga dengan pendapatan keluarga apabila tersebut memiliki pendapatan yang besar maka kualitas makanan tersebut akan bagus. Menurut DEPKES RI ,2010 kerjaan adalah jenis kegiatan yang menggunakan waktu terbanyak responden atau yang memberikan penghasilan terbesar. pekerjaan kepala keluarga rumah tangga dapat mempengaruhi tingkat pendapatan keluarga yang digunakan untuk memenuhi kebutuhan hidup. Jenis pekerjaan berhubungan erat dengan pendapatan yang merupakan faktor penting dalam menentukan kualitas dan kuantitas makanan yang dikonsumsinya (Suhardjo, 1989, 123).

Pada tabel 6 menunjukkan bahwa hampir setengahnya lansia di posyandu kelurahan pangkut adalah hipertensi sedang sebanyak 15 orang $(36.6 \%)$. Herlinah, dkk $(2013$, 292) dalam penelitiannya menunjukkan bahwa tekanan darah tinggi dapat disebabkan oleh beberapa faktor anatar lain adalah pola makan seperti asupan garam berlebih, obesitas, aktivitas fisik dan stress, faktor genetik dan usia, sistem saraf simpatis, tonus simpatid dan variasi diurnal, keseimbangan antara modulator vasokontriksi dan vasodilatasi dan pengaruh sistem otokrin setempat yang berperan dalam sistem renin, angiotensin dan aldosteron.

Berdasarkan tabel 1 dapat menunjukkan bahwa sebagian besar responden berumur di posyandu kutilang 1 kelurahan pangkut di 60-89 tahun sebanyak 21 orang $(52 \%)$. Karena pada usia-usia seperti ini fungsi organ-organ tubuh lansia mulai menurun sehingga mereka mudah terserang penyakit dan menyebabkan stress kemudian dari stress tersebut dapat mengakibatkan tekanan darah menjadi naik. Hal ini didukung dengan pendapat Potter and Perry (2005, 309) mengemukkan bahwa tekanan darah orang dewasa cenderung meningkat seiring pertambahan usia. Dari tabel 8 diketahui sebagian besar pola makan responden cukup di posyandu kutilang 1 kelurahan Pangkut dengan hipertensi sedang sebanyak 11 orang $(26,8 \%)$. 
Berdasarkan data dari tabulasi pola makan bahwa responden sering mengkonsumsi makanan tinggi garam sebanyak $21 \%$. Makanan yang asin bisa menyebab kan hipertensi karena natrium (NA) sifatnya mengikat banyak air, maka makin tinggi garam membuat volume darah meningkat. Volume darah semakin tinggi sedangkan lebar pembuluh darah tetap, maka aliran darah jadi deras, yang artinya tekanan darah menjadi semakin meningkat (Junaidi, 2012 128)

Selain itu, didapatkan hasil Rank Spearman 0,037 menunjukkan nilai $\mathrm{p}<0,05$ dengan bantuan aplikasi SPSS 16 sehingga $\mathrm{H}_{0}$ ditolak dan $\mathrm{H}_{1}$ diterima maka dapat dikatakan ada pengaruh pola makan terhadap hipertensi pada lansia di Posyandu Kutilang 1 Kelurahan Pangkut Kecamatan Arut Utara Kotawaringin Barat Kalimantan Tengah. Hasil tersebut sesuai dengan pernyataan Anggraini, dkk (2009.27).yang menyatakan bahwa hipertensi terjadi akibat beberapa faktor resiko yaitu riwayat keluarga, kebiasaan hidup yang kurang baik, durasi atau kualitas tidur dan pola diit yang kurang baik.

\section{KESIMPULAN DAN SARAN}

\section{Kesimpulan}

1. Pola makan pada lansia di posyandu Kutilang 1 Kelurahan Pangkut Kecamatan Arut Utara Utara Kotawaringin Barat Kalimantan Tengah Tahun 2017 didapatkan hasil sebagian besar responden memiliki pola makan yang cukup

2. Hipertensi pada lansia di posyandu Kutilang 1 Kelurahan Pangkut Kecamatan Arut Utara Utara Kota
Waringin Barat Kalimantan Tengah Tahun 2017 didapatkan hasil hampir setengahnya responden memiliki hipertensi sedang

3. Ada pengaruh pola makan terhadap hipertensi pada lansia di posyandu Kutilang 1 Kelurahan Pangkut Kecamatan Arut Utara Utara Kota Waringin Barat Kalimantan Tengah

\section{Saran}

1. Bagi lansia penelitian ini dapat di jadikan sebagai salah satu tindakan arternatip untuk mengurangi masalah hipertensi pada lansia.

2. Bagi petugas posyandu penelitian ini dapat dijadikan salah satu tindakan pencegahan yang dapat disampaikan melalui penyuluhan.

3. Bagi peneliti selanjutnya Perlu adanya pengkajian lebih dalam tentang fakor-faktor yang menyebabkan hipertensi dengan menggunakan variabel yang berbeda.

\section{DAFTAR PUSTAKA}

Anggraini AD, dkk, 2009 faktor-faktor yang berhubungan dengan kejadian hipertensi pada pasien yg berobat di poliklinik dewasa puskesmas bangkinang, riau : falkutas kedokteran, universitas riau.

Depkes RI 2010. rofil kesehatan indonesia. Jakarta: Depkes Republik Indonesia.

Herlinah, \& Siti arifah. 2013. Jurnal. Retrieved Agustus 6, 2017, from scribd.com: https://id.scribd.com/doc/210 
173956/Jurnal-Hubungan-

Tingkat-Pengetahuan-

Hipertensi

Junaidi, I. 2012. Hipertensi/ pengenalan, pencegahan, dan pengobatan.Jakarta: PT Bhuana Ilmu.

Morrell, r. 2011 common malayan butterflines longman. singapore

Nursalam. 2015. Konsep Penerapan Metodelogi dan Riset Keperawatan.

Jakarta:Salemba Medika

Potter. P. A. \& Perry, A. G. (2006). fundamentals of nursing: concept, process, and practice. 4/E (Terj.Yasmin Asih, et al). Jakarta: EGC

Simanjuntak j, 2011, menajemen dan epaluasi kinerja, jakarta: fakultas ekonomi ui

Suhardjo, 1989, sosio budaya gizi ipbpau pangan dan gizi, bogor 